\title{
Changes in Trophic Structure of An Exploited Fish Community At The Centennial Scale Are Linked To Fisheries and Climate Forces
}

Leonardo Durante ( $\square$ leo_durante7@hotmail.com )

University of Otago

Stephen Wing

University of Otago

Travis Ingram

University of Otago

Amandine Sabadel

University of Otago

Jeffrey Shima

Victoria University of Wellington

\section{Research Article}

Keywords: trophic structure, fish community, climate, marine food

Posted Date: August 26th, 2021

DOl: https://doi.org/10.21203/rs.3.rs-819094/v1

License: (c) (i) This work is licensed under a Creative Commons Attribution 4.0 International License.

Read Full License

Version of Record: A version of this preprint was published at Scientific Reports on March 12th, 2022. See the published version at https://doi.org/10.1038/s41598-022-08391-x. 
4 Authors: Leonardo Durante ${ }^{1 *}$, Stephen Wing ${ }^{1}$, Travis Ingram ${ }^{2}$, Amandine Sabadel ${ }^{1,2}$ and Jeffrey

\section{centennial scale are linked to fisheries and climate forces \\ Title: Changes in trophic structure of an exploited fish community at the}

\section{Affiliations:}

${ }^{1}$ Department of Marine Science - University of Otago, Dunedin, New Zealand PO Box 56.

${ }^{2}$ Department of Zoology - University of Otago, Dunedin, New Zealand PO Box 56. 
19 Abstract: Understanding how marine food webs are affected by anthropogenic stressors is an 20 important steppingstone toward the improved management of natural resources. Stable isotope

21 analysis of historical and modern samples spanning a century indicated that the niche breadth of 22 an exploited fish community increased after the expansion of New Zealand fisheries. Since the 232000 s most species increased their reliance on food webs supported by pelagic production and 24 shifted to a higher trophic level. Overall changes were coincident with ocean warming, climate oscillations, prey abundance and fishing intensity, but their effects were specific to each fish assemblage analyzed. Data derived from historical samples revealed how anthropogenic stressors can drive long-term shifts in the trophic structure of an exploited fish community. 


\section{Introduction}

Complex marine food webs support global fishery catches ${ }^{1,2}$ and are essential for ecosystem functioning and human welfare ${ }^{3,4}$. Accelerating anthropogenic stressors, such as climate change and fisheries exploitation, have driven extensive changes in the abundance ${ }^{5}$ and distribution $^{6}$ of marine organisms. While these effects have altered community composition ${ }^{7}$, little is known about their long-term impacts on the trophodynamics of marine food webs in natural systems.

Previous studies have demonstrated that ocean warming can alter the structure and drive the collapse of marine trophic pyramids ${ }^{8-13}$. Warming can increase the metabolic costs within food webs, particularly for predators and broad-spectrum omnivores, and thereby reduce fluxes of organic matter and nutrients through food webs. Changes in the rates of biomass transfer through marine food webs have also been linked to overfishing, especially of top predators ${ }^{14}$. However, these conclusions have relied heavily on mesocosm experiments and modeling of present and future climate scenarios, with baseline measurements and control treatments typically coming from already degraded ecosystems ${ }^{15,16}$. Examples from natural systems are rare but are essential if we are to understand the broader implications of natural processes and human activities for marine food webs ${ }^{17}$. For instance, overexploitation and ocean warming have had increasing influences on marine communities and ecosystem function over the last century ${ }^{7,18,19}$, with cumulative impacts observed across more than half of the global ocean ${ }^{20}$. In this context, long-term studies that incorporate archival samples to measure changes in trophic structure can provide important new insights into how the relatively recent history of human impacts have modified natural marine food webs ${ }^{21-23}$. 
New Zealand's relatively recent history of European settlement, which expanded in the early 1800's, and later fisheries industrialization provide an unparalleled opportunity to track the effects of anthropogenic impacts on its marine ecosystems ${ }^{24}$. Although Māori established in New Zealand at least 700 years ago ${ }^{25}$, the level of fisheries exploitation before widespread European settlement is estimated to be significantly lower than that after the industrialization period $^{26}$. These systems have undergone dramatic changes in recent decades ${ }^{27}$, with expansion and intensification of industrialized fisheries between 1970 and $2000^{21}$ and increasing frequency of positive ocean temperature anomalies since $1996^{22}$ (Fig. 1). The system provides an ideal opportunity to estimate the effects of accelerations in these important anthropogenic stressors with changes in the trophic structure of large marine communities. For example, while worldwide marine fisheries landings have not shown significant increases between 1970 and $2018^{4}$, in 1970 New Zealand's landings were only $25 \%$ of those reported in $2018^{21}$.

We measured naturally occurring stable isotope values from 16 exploited fish species collected from southeastern New Zealand between 1919 and 2018 (total $\mathrm{N}=658$; Table 1 and fig. S1). We used stable isotopes of carbon $\left(\delta^{13} \mathrm{C}\right)$ and nitrogen $\left(\delta^{15} \mathrm{~N}\right)$ from muscle tissue and from specific amino acids to investigate temporal shifts in niche space occupancy, trophic level, and resource use by exploited fish species. Because the species analyzed are trophically linked $^{28-32}$ and interact with multispecies fisheries in the region ${ }^{33}$, the array of species analyzed will be referred to as a community hereafter. The community was also divided into habitatspecific assemblages for further analysis.

Data analysis focused on two important themes: (1) comparing the trophic structure of modern and historical fish communities and (2) investigating the continuous effect of environmental and anthropogenic variables on the trophic structure of the fish community 
through time. Trophic level and resource use of historical fishes were compared to expected values from modern samples, while accounting for fish size and latitude of sampling (see Supplementary Materials), which are known to affect isotope values of consumers in the region $^{34,35}$. While most species were widespread throughout the whole study region, species inhabiting the slope and mid shelf were primarily collected north of latitude $44^{\circ}$ South. We evaluated long-term shifts in trophic structure of the community, based on samples collected in a large marine habitat, and their relationship with abundance of the pelagic crab, Munida gregaria, Munididae (MUN; a key prey species), the Southern Oscillation Index (SOI), sea surface temperature (SST) and the Marine Trophic Index (MTI; a measure of mean trophic level of commercial fishing landings) for New Zealand waters. M. gregaria contributes substantially to the diet of many commercial fishes in New Zealand (including reef-associated, pelagic, and deep-water species), and serves as an important link between trophic levels that span benthic and pelagic ecosystems ${ }^{28,36,37}$. On the other hand, MTI has been linked to the expansion of industrialized fisheries into new fishing grounds, increases in the amount of fishery landings and the total number of species exploited in the region ${ }^{21}$, and therefore serves as a general proxy for intensity of fisheries activities.

\section{Results}

Modern fish communities sampled since the peak of fisheries expansion in the year 2000 displayed larger niche breadths and greater interspecific trophic diversity than communities sampled before 1996 (Fig. 2). These results were primarily driven by increases in niche breadth and trophic diversity of outer shelf and slope assemblages (Fig. 2 and table S2). Large ranges of 
trophic level (inferred from $\delta^{15} \mathrm{~N}$ values) were found in the deep-water species inhabiting the edge and break of the continental shelf (slope assemblage) (Fig. 2 and table S2).

Trophic level estimates obtained from isotope values of muscle tissue and independently from specific amino acids provided a robust long-term record of change in the marine food web (Fig. S2). Due to its cost, analysis of specific amino acids was only conducted for a subset of species and samples. Nevertheless, the consistency between methods demonstrated that isotope values from basal organic matter sources were adequate for estimating trophic level from isotopic data of muscle tissue. Trophic level and/or the proportional reliance on food webs supported by pelagic (phytoplankton) relative to benthic (macroalgae) production changed over time for many of the species analyzed (Fig. 3 and table S3). Exploited fish communities shifted to greater reliance on pelagic production over the past century, as evidenced by a smaller contribution of phytoplankton to food webs before 1996 than expected from modern data (Fig. 3). Trophic levels of most key exploited fish species were significantly lower before the full expansion of industrialized fisheries than in the modern period (Fig. 3 and table S3).

The fraction of pelagic production in food webs supporting exploited fishes had a positive relationship with SOI, with no significant variability among species (Table 2). These results reflected the relationship between contribution of phytoplankton to food webs and longterm oscillations in the Pacific weather pattern, especially for fish assemblages from the continental slope and outer shelf (table S4). The average trophic levels occupied by the community decreased with increased pelagic prey abundance (MUN) and fisheries exploitation (MTI), while they increased with ocean temperature (SST) with significant variability among species (Table 2). While pelagic prey abundance varied together with trophic level of fishes from the continental shelf and mid slope, temperature and SOI were more reliable predictors of 
changes in intraspecific trophic level for the assemblage from the slope habitats (table S4). Increases in fisheries exploitation was positively correlated with intraspecific trophic level for outer shelf, slope, and mid slope assemblages. Individual species had common responses to each potential driver when grouped into assemblages (table S4).

\section{Discussion}

Reductions in overlap and redundancy within food webs have been linked to mesopredator release as a result of declines in top predator abundance, associated with fishing down marine food webs ${ }^{18}$. The community had a distinct decrease in isotopic trophic redundancy (i.e. less similar isotopic niches between species and higher trophic diversity) after the full expansion of industrialized fisheries in the 2000s (Fig. 2). Decreases of MTI after this expansion period indicated reduced abundance of higher trophic level species ${ }^{21}$, consistent with the effects of mesopredator release in the region. The expansion of New Zealand's industrialized fisheries resulted in exploitation of new offshore and deep-sea grounds, where the largest decreases in trophic redundancy were observed (table S2), indicating the spatially heterogeneous effects of fisheries on the food web dynamics of exploited species.

Larger ranges of $\delta^{13} \mathrm{C}$ values in the modern period were consistent with an increase in the diversity of alternate basal organic matter sources supporting food webs. The pattern can result in fundamental changes in food web structure, such as loss of high order consumers in inflexible trophic architectures due to anthropogenic stress, as discussed by Nagelkerken et al. ${ }^{9}$. In contrast to observations from mesocosm experiments ${ }^{9}$, species in the present study displayed greater trophic flexibility (Fig. 3), increasingly relying on food webs supported by pelagic production and feeding at higher trophic levels during the modern period. While relationships between 
resource use and environmental variables were similar for all fishes in the present study, changes in species' trophic levels reflected interspecific variation in plasticity and/or stressor exposure (Table 2). The observed patterns indicate that the sources of organic matter supporting fisheries food webs were more affected by oscillatory environmental forces, while intraspecific trophic level was closely tied to constraints on the trophic ecology of each species, affected by both environmental and anthropogenic stressors. The observed variability might be specific to each fish habitat or depth, since species effects were non-significant when assemblages were analyzed separately (table S4).

Long-term warming and marine heatwaves have been correlated with increased pelagic production and local extinction of macroalgae in the study region ${ }^{38,39}$, likely resulting in the observed shift in basal organic matter sources supporting marine food webs. The increase in trophic level may have been driven by competition for limited resources leading species to feed upon other secondary consumers ${ }^{9}$. For example, Pinkerton et al..$^{40}$ demonstrated that trophic levels of fishes are likely to increase with decreases in their abundance in New Zealand.

Observed intraspecific increases in trophic level between time periods in the present study are coincident with decreases in abundance for many of the key species analyzed ${ }^{33}$ (Fig. 3).

The fish community fed at lower trophic levels during years with more intense fishing activities characterized by high marine trophic index (MTI) values (Table 2). Exploitation has been shown to drive high trophic level species to shift prey fields, lowering their trophic level and altering the flux of energy through food webs in overexploited regions ${ }^{41-45}$. Fishing activities impacted the trophic level occupied by fish species primarily in the outer shelf, slope and mid slope assemblages (table S4), which were the habitats most affected by exploitation during the time frame of the present analysis ${ }^{21}$. 
Although positive and negative SOI values indicated warmer La Niña and colder El Niño conditions in New Zealand, respectively, SOI had the reverse effect of SST on intraspecific trophic levels (Table 2 and Table S4). Furthermore, fishes collected during years of positive SOI had a higher reliance on food webs supported by pelagic production. The observed pattern indicates that along with the overall warming trend, oscillatory changes in temperature and rainfall, likely linked to marine heatwaves, can also influence trophic structure of fisheries food webs.

When abundance of the pelagic primary consumer M. gregaria (MUN) is high, pelagic prey can represent a large proportion of the diet of the exploited fish species in southeastern New Zealand $^{28,46}$, decreasing a consumer's trophic level (Table 2). Reduction of M. gregaria abundance over time was therefore linked to the overall increased trophic level of fish species. This pattern was observed for most fish assemblages (table S4) and highlights the importance of M. gregaria, and likely other invertebrate species, for maintenance of the food web supporting commercial fish species in New Zealand.

Due to sample availability, especially from the historical period, the comparison between modern and historical ecological states is sample rich but coarse in resolution, while continuous analysis of environmental and fisheries data presents high year-to-year resolution but low replication. This dissimilarity can result in contradictory results depending on when samples were collected. For example, while exploitation was related to a decrease in trophic level, fish species showed an increase in trophic level together with an increase in fisheries activities over time throughout the whole period. The observed pattern is influenced by many recent samples collected during the peak of fisheries expansion, with a lack of samples collected between the year 2000 and 2012. However, both results are correct and supported by the available data. 
Ocean warming can cause shifts in productivity and biomass in communities with

192

193

194

195

196

197

198

199

200

201

202

203

204

205 relatively inflexible trophic architecture, which can strongly reduce stability of marine food webs $^{9,13}$. Furthermore, from a modeling approach, overfishing has been shown to change species composition of fish communities and alter marine food webs ${ }^{14,47}$. Here we have provided evidence for long-term changes in the trophic structure of an exploited fish community. The present study was based on specimens collected over a $100 \mathrm{yr}$ period in a large marine habitat during times with contrasting temperature regimes and fishing intensity. Continuous changes in trophic structure were related to environmental, biological, and anthropogenic stressors, and were manifested differently among coastal, shelf and continental slope fish assemblages. While warming alone may not affect the trophic structure of consumers ${ }^{9}$, shifts in trophic architecture are a possible outcome in natural systems affected by changing exploitation, prey availability and climate $^{48}$, with important consequences for trophodynamics in fisheries ecosystems.

\section{Methods}

\section{Sample collection}

Sixteen species of fish were collected along the east coast of the South Island between 2017 and 2018 (Table 1 and S1). Coastal species were collected during scientific cruises onboard the RV Polaris II or provided by recreational anglers, while fishes that inhabit offshore waters were mainly provided by commercial fishers or from the Canterbury Bight and Pegasus Bay trawl survey ${ }^{49}$. Deeper water species, such as lookdown dory (Cyttus traversi, Cyttidae), orange roughy (Hoplostethus atlanticus, Trachichthyidae) and hoki (Macruronus novaezelandiae, Merlucciidae) were acquired from the Chatham Rise trawl surveys ${ }^{50}$. Specimens collected onboard research vessels were measured for total length and head length 
214 and were frozen and taken to the laboratory to sample muscle tissue. Since samples provided by

215 fishers often consisted of fish heads only, a linear regression between total length and head

216 length was calculated, to estimate total length of those specimens and include them to the main

217 analysis (table S6).

To access the stable isotope values and estimate trophic parameters of fish species before

219 the present date, specimens were retrieved from the Otago Museum and the Museum of New

220 Zealand Te Papa Tongarewa collections, spanning 1919 to 2012, most comprising the

221 "historical” sample group (period between 1919 and 1996). Muscle tissue $\left(1 \mathrm{~cm}^{3}\right)$ was sampled

222 from the dorsal musculature of all specimens for isotope analysis. Tissue samples from museum

223 collections were then treated with deionized water for one week to remove excess preservatives

224 before analysis ${ }^{51}$. Temporal changes in the environment and fisheries activities have marked the 225 separation between historical and modern periods, allowing the present study to investigate its

226 effects on the trophic structure of fish communities. While the historical period was marked by

227 the development and extension of New Zealand fisheries and relatively colder temperatures,

228 New Zealand fisheries have reached their peak and sea surface temperature anomalies have

229 presented a steady increase during the modern period ${ }^{21,22}$ (Fig. 1).

231 of the primary producers supporting food webs. Coastal (macroalgae), and pelagic

232 (phytoplankton) primary producers were assumed to be the main contributors of organic matter

233 to the fish communities within the study region and used as isotope baselines in the present

234 study. $\delta^{13} \mathrm{C}$ and $\delta^{15} \mathrm{~N}$ values of macroalgae were obtained from Otago (-15.93 and 8.1\%o),

235 Kaikoura (-13.46 and 8.22\%o) and the Marlborough Sounds (-14.86 and 6.84\%o) $\left(^{44}\right.$ and

236 unpublished data). Similarly, isotopic values of phytoplankton were inferred from samples of 
237 suspended particulate organic matter (SPOM) from inside the Canterbury Bight (-24 and

$238 \quad 5.45 \%$ ), along the Kaikoura coast (-21.1 and 7.39\%o) and the Marlborough Sounds (-22.75 and

$2396.29 \%$ ) were used ${ }^{35,44}$. Both macroalgae and SPOM samples were collected concomitantly with

240 the collection of specimens in the modern period.

\section{Sample preparation and bulk analysis}

Muscle tissues were oven-dried at $60{ }^{\circ} \mathrm{C}$ for $72 \mathrm{~h}$ and gound to a fine and homogenous

244 powder with mortar and pestle. All equipment was cleaned with low-linting Kimwipes® and 245 ethanol and air-dried between samples to avoid cross-contamination. Between 0.8 and $1.2 \mathrm{mg}$ of

246 each sample was packed in $3 \times 5 \mathrm{~mm}$ tin capsules and analyzed by combustion in an elemental 247 analyzer (Carlo Erba NC2500) coupled with a Europa Scientific 20-20 ANCA Mass

248 Spectrometer operating in continuous flow. Delta values were normalized and reported against 249 the international standards Vienna Pee Dee Belemnite (VPDB) and atmospheric $\mathrm{N}_{2}$ (AIR) for $250 \quad \delta^{13} \mathrm{C}$ and $\delta^{15} \mathrm{~N}$, respectively. The ratio between the molar amount of carbon and nitrogen in each 251 sample $(\mathrm{C}: \mathrm{N})$ was also reported. Normalization was made by 3-point calibration with two 252 glutamic acid international reference materials and a laboratory EDTA standard (Elemental 253 Microanalysis) for carbon (USGS-40 =-26.2 \%o, USGS-41 = 37.8 \%o, EDTA $=-38.93 \%$ ) and 254 nitrogen (USGS-40 $=-4.52 \%$, USGS-41 $=47.57 \%$, EDTA $=-0.73 \%$ ). Analytical precision 255 was checked by comparing results from analyzed quality control standards EDTA-OAS and 256 IAEA MA-A-1 (Copepod) against accepted values. All measured values for the quality control 257 standards were in the range of accepted values. Additionally, one sample of fish muscle tissue was analyzed in every run so results could be corrected for in-between run variability. 
Because lipids are depleted in $\delta^{13} \mathrm{C}$ compared to protein and carbohydrates, changes in

260 lipid content in the samples can have a large effect in $\delta^{13} \mathrm{C}$ values that are not linked to trophic

261 parameters. In the present study the following normalization equation was applied to all samples

262 collected in 2017 and 2018 to account for variation in lipid concentrations, after Post et al. ${ }^{53}$ :

$$
\delta^{13} \mathrm{C}_{\text {Normalized }}=\delta^{13} \mathrm{C}_{\text {Untreated }}-3.32+0.99 * \mathrm{C}: \mathrm{N}
$$

Here, $\delta^{13} \mathrm{C}_{\text {Untreated }}$ represents raw $\delta^{13} \mathrm{C}$ measurements and $\mathrm{C}: \mathrm{N}$ the carbon to nitrogen ratio

$$
\begin{gathered}
\delta^{15} \mathrm{~N}=11.25+0.71 \times \delta^{15} \mathrm{~N}_{\text {preserved }}+0.27 \times \delta^{13} \mathrm{C}_{\text {preserved }}-0.21 \text { proportion of } \mathrm{N}_{\text {preserved }} \\
\delta^{13} \mathrm{C}_{\text {lipid free }}=-8.42+0.07 \times \delta^{15} \mathrm{~N}_{\text {preserved }}+0.76 \times \delta^{13} \mathrm{C}_{\text {preserved }}+0.97 \times \text { preserved } \mathrm{C}: \mathrm{N}_{\text {preserved }}
\end{gathered}
$$

$\delta^{13} \mathrm{C}$ values of primary producers have also been globally influenced by anthropogenic

275 activities since the industrialization period in the 1950 ' $\mathrm{s}^{54,55}$, and to compare with present values 
those changes need to be taken into account. These processes are known to influence fishes from different trophic levels and have been reported for the Otago region ${ }^{56}$. The Suess effect (decrease of atmospheric $\delta^{13} \mathrm{C}$ of $\mathrm{CO}_{2}$ ) was corrected after ${ }^{57}$, which predicts a decrease in $\delta^{13} \mathrm{C}_{\mathrm{Bulk}}$ of on average $0.011 \%$ per year $(-0.014 \pm 0.001 \%$ to $-0.006 \pm 0.001 \%$ ) in the ventilated South Pacific Ocean.

\section{Amino acid stable isotope analyses}

To test the accuracy of trophic level estimates when primary producers could not be sampled (historical period), compound-specific stable isotope analysis of amino acids (CSIAAA) were used ${ }^{58,59}$. Nitrogen isotope in different amino acids $\left(\delta^{15} \mathrm{~N}_{\mathrm{AA}}\right)$ fractionate in contrasting ways between trophic levels and can be classified as source (no-to-little fractionation of $\delta^{15} \mathrm{~N}$ ) and trophic (large fractionation of $\delta^{15} \mathrm{~N}$ ). Consequentially, use of $\delta^{15} \mathrm{~N}_{\mathrm{AA}}$ allows researchers to access information regarding a specimen's trophic level from a single muscle tissue sample ${ }^{60}$. The technique is especially useful when isotope values of primary producers for the estimation of trophic level are not known or cannot be sampled, allowing one to investigate changes in trophic parameters at large spatial and temporal scales ${ }^{61-63}$. For example, the relationship between $\delta^{15} \mathrm{~N}$ of Glutamic acid ( $\delta^{15} \mathrm{~N}_{\mathrm{Glx}}$, trophic AA) and $\delta^{15} \mathrm{~N}$ of Phenylalanine ( $\delta^{15} \mathrm{~N}_{\text {Phe, }}$, source AA) have been used to accurately estimate trophic level of aquatic animals ${ }^{59}$.

Amino acids were extracted by hydrolyzing $2.5 \mathrm{mg}$ of sample with $2 \mathrm{ml} 6 \mathrm{M} \mathrm{HCl}$ at 110 ${ }^{\circ} \mathrm{C}$ for 24 hours in a $\mathrm{N}_{2}$ atmosphere. An internal standard, norleucine $(50 \mu \mathrm{of} 1 \mathrm{mg} / \mathrm{ml}$ solution), was added to monitor the wet chemistry and AA stable isotope values. Solutes were then dried under a gentle flow of $\mathrm{N}_{2}$ at $60{ }^{\circ} \mathrm{C}$ and subsequently converted into N-Acetylisopropyl (NAIP) ester derivatives following the protocol described in ${ }^{64}$, modified from ${ }^{65}$. See Sabadel $e t$ 
$299 a l$. for full methods details. $\delta^{15} \mathrm{~N}_{\mathrm{AA}}$ was measured by gas chromatography/combustion/isotope 300 ratio mass spectrometer (GC-IRMS), using a Thermo Trace gas chromatograph, the GC

301 combustion III interface, and a Deltaplus XP isotope ratio mass spectrometer (Thermo Fisher

302 Scientific). $200 \mathrm{nl}$ aliquots of derivatized AA were injected in an inlet at $270{ }^{\circ} \mathrm{C}$ in spitless

303 mode, carried by helium at $1.4 \mathrm{ml} \mathrm{min}^{-1}$ and separated on a VF-35ms column (30 m long, 0.32

$304 \mathrm{~mm}$ ID and a $1.0 \mu \mathrm{m}$ film thickness). Samples were analyzed in duplicates or triplicates along

305 with amino acid standards of known isotopic composition (measured by EA-IRMS) and

306 bracketing measurement of every two samples. Each run contained no more than 10 samples.

307 Similar to bulk, $\delta$ values from AA were reported following the conventional method of

308 expressing $\delta$ at natural abundance, in per mil (\%o), relative to an international standard of

309 atmospheric $\mathrm{N}_{2}$ for $\delta^{15} \mathrm{~N}_{\mathrm{AA}}{ }^{66}$.

310 Glutamine + glutamic acid (Glx) and phenylalanine (Phe) were measured from 50

311 samples from the historical period and comprising eight species. Note that during the hydrolysis

312 step glutamine is converted to glutamic acid. Precision (1SD) of $\delta^{15} \mathrm{~N}_{\mathrm{AA}}$ ranged from 0 to $1.1 \%$

313 with a mean of $0.4 \%$.

\section{Trophic parameter calculations}

Because the variability of isotopic baselines can affect the bulk isotope values of fish

317 muscle tissue, we used region-specific baselines from the two main primary producers,

318 macroalgae and SPOM (corresponding mainly to phytoplankton ${ }^{35}$ ), to estimate trophic level and

319 percentage phytoplankton supporting the food webs for each fish. For the analysis, a two-step

320 iterative procedure based on bulk isotope values was used to generate a mass balance model,

321 following Phillips and Gregg $(2001)^{67}$. First an approximation of the contribution of each 
322 organic matter source to a fish's $\delta^{13} \mathrm{C}$ value was calculated from plotted $\delta^{15} \mathrm{~N}$ vs. $\delta^{13} \mathrm{C}$ values.

323 The results were then used to estimate the corresponding $\delta^{15} \mathrm{~N}$ value of the mixture of organic

324 matter sources supporting each specimen $\left(\delta^{15} \mathrm{~N}_{\text {resource }}\right)^{68}$, assuming the same contribution from the

$325 \delta^{15} \mathrm{~N}$ pool. Trophic level was then calculated for each fish using its own $\delta^{15} \mathrm{~N}$ value

$326\left(\delta^{15} \mathrm{~N}_{\text {Consumer }}\right)$ :

$$
\mathrm{TL}=1+\left(\delta^{15} \mathrm{~N}_{\text {consumer }}-\delta^{15} \mathrm{~N}_{\text {resource }}\right) / \mathrm{TDF}
$$

Because of the differences in diet, i.e. invertivore and piscivores, trophic discrimination factor (TDF) was assumed to be 3.4\% (SD 1) for fishes mainly feeding on invertebrates and $2.3 \%$ (SE 0.28) for species with reported diet being composed by more than $50 \%$ fish $^{69,70}($ table S1). The result of the equation was then iterated back into the mass balance model until a stable solution was obtained for both the mixture of organic matter sources and TL for each specimen. A trophic discrimination factor for aquatic environments of $0.5 \%$ (SE 0.17 ) was used for $\delta^{13} \mathrm{C}^{69}$.

To test the accuracy of trophic level estimates from bulk isotopes we compared those estimates with trophic level calculated from CSIA-AA. Trophic levels based on amino acid isotope results were calculated based on differences between $\delta^{15} \mathrm{~N}_{\mathrm{Glx}}$ and $\delta^{15} \mathrm{~N}_{\text {Phe }}$, following Chikaraishi et al::

$$
\mathrm{TL}_{\mathrm{Glx} \text {-phe }}=1+\left(\delta^{15} \mathrm{~N}_{\mathrm{Glx}}-\delta^{15} \mathrm{~N}_{\mathrm{Phe}}-3.4\right) / \mathrm{TDF}_{\mathrm{Glx} \text {-Phe }}
$$

With 3.4\%o the difference between $\delta^{15} \mathrm{~N}_{\mathrm{Glx}}$ and $\delta^{15} \mathrm{~N}_{\text {Phe }}$ in aquatic cyanobacteria and algae 59. Similar to trophic level estimates from the mixing model, the trophic discrimination factor representing the difference in fractionation per trophic level of $\delta^{15} \mathrm{~N}_{\mathrm{Glx}}$ and $\delta^{15} \mathrm{~N}_{\mathrm{Phe}}$ (TDFGlx-Phe), was chosen according to the fish species' $\operatorname{diet}^{71}$. In their feeding experiment study, McMahon and co-authors found that fishes fed on high protein diets, where the AA composition were 
342 similar to the fishes' muscle tissue, presented a smaller $\mathrm{TDF}_{\mathrm{Glx} \text {-Phe }}$ than fishes feeding on an

343 omnivorous diet. Therefore, in the present study a $\mathrm{TDF}_{\mathrm{Glx}-\mathrm{Phe}}$ value of $7.6 \%$ was used for

344 species with fish contribution to its diet lower than $50 \%^{59}$, while a value of 5.9\%o was chosen for 345 piscivore $\operatorname{species}^{71}$ (table S1).

Data analysis

Changes in niche width in the whole fish community and within each assemblage (see Table S1) were investigated between periods using ellipse-based versions of Layman's metrics estimated from Bayesian inference, using the SIBER package in $\mathrm{R}^{72,73}$. The use of ellipse-based metrics is suitable for comparisons between communities with different samples sizes, with improved estimates and reduced uncertainty compared to original metrics. For example, total area of convex hull (TA) of the $\delta^{13} \mathrm{C}$ and $\delta^{15} \mathrm{~N}$ biplot, or isotopic space, can be easily biased by large isotope values from few individuals, while the calculation of the Standard Ellipse Areas corrected for small sample sizes $\left(\mathrm{SEA}_{\mathrm{c}}\right)$ provides Bayesian distributions that reflect the uncertainty of estimates, resulting in more robust and less biased comparisons ${ }^{72}$. Similarly, the mean Euclidian distance from each species to the $\delta^{15} \mathrm{~N}$ and $\delta^{13} \mathrm{C}$ centroid of the whole food web (CD) is a metric of average trophic diversity that is also affected by trophic packing ${ }^{73}$. Moreover, the mean nearest neighbor distance (MNND) and the standard deviation (SDNND) of the same plot can be used as proxies for trophic packing and its evenness, respectively. muscle tissue and hamper investigations of isotopic niche space. For practicality, museums tend to keep only small to medium size specimens in their wet collections, creating a bias in historical 364 samples towards small individuals. To account for those effects, before Layman's metrics 
analysis, large specimens from the modern period and small from museum collections were excluded until both groups achieved equal distributions of total length (Wilcoxon test and ANOVA, $\mathrm{p}>0.05)$. Likewise, isotope values of each species were only compared when samples were collected from the same latitude range in both periods, historical and modern.

To investigate how the trophic level and percentage phytoplankton supporting the fish community have varied over time, the anomalies of those parameters were calculated, by comparison to modern samples. We fitted general linear models for each species collected in the modern group, with percentage phytoplankton and trophic level as response variable, and latitude and specimen's total length as explanatory variables. Coefficients were calculated with a least square approach, which is sensitive to outliers and performs well with noisy, collinear and incomplete variables, being suitable for analysis of complex models in chemistry and biology ${ }^{74}$. All combinations of variables were tested and linear models with the lowest Akaike Information Criteria corrected for small sample sizes $\left(\mathrm{AIC}_{\mathrm{c}}\right)$ were selected. When latitude and/or size contributed significantly to the estimate of trophic level and percentage phytoplankton, the resulting equation was used to estimate the expected percentage phytoplankton and trophic level of individuals. When latitude and total length did not contribute to the model, average values of modern species were used as predicted percentage phytoplankton and trophic level values. In both cases, groups were only analyzed when samples were collected from similar ranges of latitude and/or had similar range of total length in both periods, historical and modern.

The difference between real (estimated through bulk isotopes) and expected (modeled through multiple linear regression) resulted in the values-predicted percentage phytoplankton and trophic level. To investigate changes in percentage phytoplankton and trophic level of the exploited community, values-predicted were plotted for communities sampled before the full 
expansion of industrialized fisheries in New Zealand (before 1996, or historical). Differences in value-predicted percentage phytoplankton and trophic level between historical and modern samples were analyzed for each separate species using a PERMANOVA. Unrestricted permutations $(10,000)$ of the dissimilarity matrices calculated with Euclidian distance were used for each variable separately. PERMANOVA is a type of analysis of variance that uses permutation to compute statistical tests instead of statistical tables, and does not assume linearity or normality ${ }^{75}$.

The effects of sea surface temperature (SST), Southern Oscillation Index (SOI), fisheries activities (MTI) and abundance of pelagic prey (MUN) were investigated by fitting general linear models to value-predicted percentage phytoplankton and trophic level. Yearly anomaly values of the independent variables were used in the models, considering an average between 1953 and 2018. SOI is calculated with the difference in air pressure between Tahiti and Darwin; while low SOI values indicate El Niño events, La Niña is identified by high SOI values. The east coast of the South Island of New Zealand can experience droughts during both anomalies, while La Niña is usually associated with higher temperatures ${ }^{76}$. SST was recorded at the Portobello Marine Laboratory of the University of Otago (PML), and although it represents a localized proxy of ocean warming, it has been reported to follow large scale processes, such as the overall increase in temperatures in boundary currents associated with changes in wind regimes $^{22}$. MUN was inferred from the sum of the sightings of $M$. gregaria from PML in each year $^{37,46}$, and MTI calculated for New Zealand waters was used as a proxy of the state of fisheries expansion in a given year, after Durante $e t a l .^{21}$. Results from Durante et al. ${ }^{21}$ comprise the most accurate MTI values available for the New Zealand region, with data amalgamated from Fisheries New Zealand and the Food and Agriculture Organization of the United Nations 
411 and annual catches identified to species level. Because MTI was only calculated until 2015, the

412 value from 2015 was used in the years 2017 and 2018. As shown by Durante et al., MTI values

413 for New Zealand have not varied greatly in the most recent years, which justifies the

414 approximation when comparing to long-term shifts in MTI. Yearly values of SOI, SST, MUN

415 and MTI did not show strong correlation (Pearson's coefficient correlation from -0.32 to 0.42)

416 and were therefore fit for multiple linear model analysis. Species were analyzed as a whole

417 community and as four different assemblages (inner shelf, outer shelf, slope and mid slope)

418 according to their habitat use and composition after Francis et al. and Beentjes et al. (Table S1).

419 All statistical analysis were undertaken with R 3.6.3 ${ }^{79}$, JMP 14.0.0 ${ }^{80}$ and PRIMER 6.1.12 ${ }^{81}$.

\section{References and Notes}

422 1. Kroodsma, D. A. et al. Tracking the global footprint of fisheries. Science 359, 904-908 (2018).

2. Luong, A. D., Dewulf, J. \& De Laender, F. Quantifying the primary biotic resource use by fisheries: A global assessment. Science of The Total Environment 719, 137352 (2020).

3. Pauly, D. How the global fish market contributes to human micronutrient deficiencies. Nature 574, 41-42 (2019).

4. FAO. The State of World Fisheries and Aquaculture 2020. (FAO, 2020). doi:10.4060/ca9229en indicators to evaluate the ecosystem effects of fishing. ICES Journal of Marine Science 62, 384-396 (2005). 
6. Perry, A. L. Climate Change and Distribution Shifts in Marine Fishes. Science 308, 19121915 (2005).

7. Novaglio, C., Smith, A. D. M., Frusher, S. \& Ferretti, F. Identifying historical baseline at the onset of exploitation to improve understanding of fishing impacts. Aquatic Conservation: Marine and Freshwater Ecosystems 30, 475-485 (2020).

8. Nagelkerken, I. \& Connell, S. D. Global alteration of ocean ecosystem functioning due to increasing human CO 2 emissions. Proceedings of the National Academy of Sciences 112, 13272-13277 (2015).

9. Nagelkerken, I., Goldenberg, S. U., Ferreira, C. M., Ullah, H. \& Connell, S. D. Trophic pyramids reorganize when food web architecture fails to adjust to ocean change. Science 832, 829-832 (2020).

10. Lemoine, N. P. \& Burkepile, D. E. Temperature-induced mismatches between consumption and metabolism reduce consumer fitness. Ecology 93, 2483-2489 (2012).

11. Scheffer, M., Carpenter, S., Foley, J. A., Folke, C. \& Walker, B. Catastrophic shifts in ecosystems. Nature 413, 591-596 (2001).

12. Moore, J. K. et al. Sustained climate warming drives declining marine biological productivity. Science 359, 1139-1143 (2018).

13. Ullah, H., Nagelkerken, I., Goldenberg, S. U. \& Fordham, D. A. Climate change could drive marine food web collapse through altered trophic flows and cyanobacterial proliferation. PLOS Biology 16, e2003446 (2018).

14. Maureaud, A. et al. Global change in the trophic functioning of marine food webs. PLOS ONE 12, e0182826 (2017). 
455 15. Wernberg, T. et al. Climate-driven regime shift of a temperate marine ecosystem. Science $456 \quad 353,169-172(2016)$.

457 16. Pauly, D. Anecdotes and the shifting baseline syndrome of fisheries. Trends in Ecology \& $458 \quad$ Evolution 10, 430 (1995).

459 17. Chown, S. L. Marine food webs destabilized. Science 369, 770-771 (2020).

460 18. Saporiti, F. et al. Longer and less overlapping food webs in anthropogenically disturbed 461 marine ecosystems: confirmations from the past. PLoS ONE 9, 1-13 (2014).

462 19. Gilby, B. L. et al. Human actions alter tidal marsh seascapes and the provision of 463 ecosystem services. Estuaries and Coasts (2020). doi:10.1007/s12237-020-00830-0

464 20. Halpern, B. S. et al. Recent pace of change in human impact on the world's ocean. $465 \quad$ Scientific Reports 9, 11609 (2019).

466 21. Durante, L. M., Beentjes, M. P. \& Wing, S. R. Shifting trophic architecture of marine fisheries in New Zealand: Implications for guiding effective ecosystem-based management. Fish and Fisheries 21, 813-830 (2020).

22. Shears, N. T. \& Bowen, M. M. Half a century of coastal temperature records reveal complex warming trends in western boundary currents. Scientific Reports 7, 1-9 (2017).

471 23. Wing, S. R. \& Wing, E. Prehistoric fisheries in the Caribbean. Coral Reefs 20, 1-8 (2001).

472 24. Halpern, B. S. et al. A Global Map of Human Impact on Marine Ecosystems. Science 319, 473 948-952 (2008).

25. Irwin, G. \& Walrond, C. 'When was New Zealand first settled? - Extinction and decline'. 
http://www.teara.govt.nz/en/when-was-new-zealand-first-settled/page-7. (Accessed: 4th June 2019)

26. Johnson, D. \& Haworth, J. Hooked - The Sory of New Zealand Fishing Industry. (Hazard Press, 2004).

27. Urlich, S. C. \& Handley, S. J. From 'clean and green' to 'brown and down': A synthesis of historical changes to biodiversity and marine ecosystems in the Marlborough Sounds, New Zealand. Ocean \& Coastal Management 198, 105349 (2020).

28. Graham, D. H. Food of fishes of Otago Harbour and Adjacent Sea. Royal Society of New Zealand 421-436 (1939).

29. Hanchet, S. Diet of spiny dogfish, Squalus acanthias Linnaeus, on the east coast, South Island, New Zealand. Journal of Fish Biology 39, 313-323 (1991).

30. Connell, A., Dunn, M. \& Forman, J. Diet and dietary variation of New Zealand hoki Macruronus novaezelandiae. New Zealand Journal of Marine and Freshwater Research 44, 289-308 (2010).

31. Forman, J. \& Dunn, M. The influence of ontogeny and environment on the diet of lookdown dory, Cyttus traversi. New Zealand Journal of Marine and Freshwater Research 44, 329-342 (2010).

32. Horn, P. L., Forman, J. S. \& Dunn, M. R. Dietary partitioning by two sympatric fish species, red cod ( Pseudophycis bachus ) and sea perch ( Helicolenus percoides ), on Chatham Rise, New Zealand. Marine Biology Research 8, 624-634 (2012).

33. Fisheries New Zealand. Fisheries Assessment Plenary, May 2020: stock assessments and stock status. (2020). 
498 34. Ladds, M., Pinkerton, M. H., Jones, E., Durante, L. \& Dunn, M. Relationship between morphometrics and trophic levels in deep-sea fishes. Marine Ecology Progress Series 637, 225-235 (2020).

501

502

35. Durante, L. M. et al. Oceanographic transport along frontal zones forms carbon, nitrogen , and oxygen isoscapes on the east coast of New Zealand : Implications for ecological studies. Continental Shelf Research 216, 1-15 (2021).

36. Funes, M., Irigoyen, A. J., Trobbiani, G. A. \& Galván, D. E. Stable isotopes reveal different dependencies on benthic and pelagic pathways between Munida gregaria ecotypes. Food Webs 17, 1-9 (2018).

37. Zeldis, J. R. \& Jillett, J. B. Aggregation of pelagic Munida gregaria (Fabricius)

(Decapoda, Anomura) by coastal fronts and internal waves. Journal of Plankton Research 4, 839-857 (1982).

38. Chiswell, S. M. \& Sutton, P. J. H. Relationships between long-term ocean warming, marine heat waves and primary production in the New Zealand region. New Zealand Journal of Marine and Freshwater Research 1-22 (2020). doi:10.1080/00288330.2020.1713181

39. Thomsen, M. S. et al. Local Extinction of Bull Kelp (Durvillaea spp.) Due to a Marine Heatwave. Frontiers in Marine Science 6, 1-10 (2019).

40. Pinkerton, M. H. et al. Changes to the food-web of the Hauraki Gulf during the period of human occupation: a mass-balance model approach. New Zealand Aquatic Environment and Biodiversity Report No. 160. (2015).

41. Garrison, L. Fishing effects on spatial distribution and trophic guild structure of the fish 
community in the Georges Bank region. ICES Journal of Marine Science 57, 723-730 (2000).

42. Link, J. S. \& Garrison, L. P. Changes in piscivory associated with fishing induced changes to the finfish community on Georges Bank. Fisheries Research 55, 71-86 (2002).

43. Wainright, S. C., Fogarty, M. J., Greenfield, R. C. \& Fry, B. Long-term changes in the Georges Bank food web: trends in stable isotopic compositions of fish scales. Marine Biology 115, 481-493 (1993).

44. Udy, J. A. et al. Regional differences in supply of organic matter from kelp forests drive trophodynamics of temperate reef fish. Marine Ecology Progress Series 621, 19-32 (2019).

45. Koenigs, C., Miller, R. \& Page, H. Top predators rely on carbon derived from giant kelp Macrocystis pyrifera. Marine Ecology Progress Series 537, 1-8 (2015).

46. Zeldis, J. Ecology of Munida gregaria (Decapoda, Anomura) distribution and abundance, population dynamics and fisheries. Marine Ecology Progress Series 22, 77-99 (1985).

47. Myers, R. A., Baum, J. K., Shepherd, T. D., Powers, S. P. \& Peterson, C. H. Cascading effects of the loss of apex predatory sharks from a coastal ocean. Science 315, 1846-1850 (2007).

48. Kirby, R. R., Beaugrand, G. \& Lindley, J. A. Synergistic Effects of Climate and Fishing in a Marine Ecosystem. Ecosystems 12, 548-561 (2009).

49. MacGibbon, D. J., Beentjes, M. P., Lyon, W. L. \& Ladroit, Y. Inshore trawl survey of Canterbury Bight and Pegasus Bay, April-June 2018 (KAH1803). New Zealand Fisheries Assessment Report 2019/03. (2019). 
542 50. Stevens, W. D., O’Driscoll, R. L., Ballara, S. L. \& Schimel, A. C. G. Trawl survey of hoki and middle-depth species on the Chatham Rise, January 2018 (TAN1801). New Zealand Fisheries Assessment Report 2018/41. (2018).

51. Durante, L. M., Sabadel, A. J. M., Frew, R. D., Ingram, T. \& Wing, S. R. Effects of fixatives on stable isotopes of fish muscle tissue: implications for trophic studies on preserved specimens. Ecological Applications 30, 1-16 (2020).

52. Post, D. M. et al. Getting to the fat of the matter: models, methods and assumptions for dealing with lipids in stable isotope analyses. Oecologia 152, 179-189 (2007).

53. Post, D. M. Using stable isotopes to estimate trophic position: models, methods, and assumptions. Ecology 83, 703-718 (2002).

54. Verburg, $\mathrm{P}$. The need to correct for the Suess effect in the application of $\delta^{13} \mathrm{C}$ in sediment of autotrophic Lake Tanganyika, as a productivity proxy in the Anthropocene. Journal of Paleolimnology 37, 591-602 (2007).

55. Keeling, C. D. The Suess effect: ${ }^{13}$ Carbon- $-{ }^{14}$ Carbon interrelations. Environment International 2, 229-300 (1979).

56. Sabadel, A., Durante, L. \& Wing, S. Stable isotopes of amino acids from reef fishes uncover Suess and nitrogen enrichment effects on local ecosystems. Marine Ecology Progress Series 647, 149-160 (2020).

57. Eide, M., Olsen, A., Ninnemann, U. S. \& Eldevik, T. A global estimate of the full oceanic ${ }^{13} \mathrm{C}$ Suess effect since the preindustrial. Global Biogeochemical Cycles 31, 492-514 (2017).

58. McMahon, K. W. \& McCarthy, M. D. Embracing variability in amino acid $\delta^{15} \mathrm{~N}$ 
fractionation: mechanisms, implications, and applications for trophic ecology. Ecosphere 7, 1-26 (2016).

59. Chikaraishi, Y. et al. Determination of aquatic food-web structure based on compoundspecific nitrogen isotopic composition of amino acids. Limnology and Oceanography: Methods 7, 740-750 (2009).

60. Whiteman, J. P., Smith, E. A. E., Besser, A. C. \& Newsome, S. D. A guide to using compound-specific stable isotope analysis to study the fates of molecules in organisms and ecosystems. Diversity 11, 1-18 (2019).

61. Hilton, G. M. et al. A stable isotopic investigation into the causes of decline in a subAntarctic predator, the rockhopper penguin. Global Change Biology 12, 611-625 (2006).

62. Lorrain, A. et al. Nitrogen and carbon isotope values of individual amino acids: a tool to study foraging ecology of penguins in the Southern Ocean. Marine Ecology Progress Series 391, 293-306 (2009).

63. Quillfeldt, P. \& Masello, J. F. Compound-specific stable isotope analyses in Falkland Islands seabirds reveal seasonal changes in trophic positions. BMC Ecology 20, 1-12 (2020).

64. Sabadel, A. J. M., Woodward, E. M. S., Van Hale, R. \& Frew, R. D. Compound-specific isotope analysis of amino acids: A tool to unravel complex symbiotic trophic relationships. Food Webs 6, 9-18 (2016).

65. Styring, A. K. et al. Practical considerations in the determination of compound-specific amino acid $\delta^{15} \mathrm{~N}$ values in animal and plant tissues by gas chromatography-combustionisotope ratio mass spectrometry, following derivatisation to their $\mathrm{N}$-acetylisopropyl e. 
Rapid Communications in Mass Spectrometry 26, 2328-2334 (2012).

587 66. Coplen, T. B. Guidelines and recommended terms for expression of stable-isotope-ratio

69. McCutchan, J. H., Lewis, W. M., Kendall, C. \& McGrath, C. C. Variation in trophic shift 68. Jack, L. \& Wing, S. R. Individual variability in trophic position and diet of a marine omnivore is linked to kelp bed habitat. Marine Ecology Progress Series 443, 129-139 (2011). for stable isotope ratios of carbon, nitrogen, and sulfur. Oikos 102, 378-390 (2003).

70. Hussey, N. E. et al. Rescaling the trophic structure of marine food webs. Ecology Letters 17, 239-250 (2014).

71. McMahon, K. W., Thorrold, S. R., Elsdon, T. S. \& Mccarthy, M. D. Trophic discrimination of nitrogen stable isotopes in amino acids varies with diet quality in a marine fish. Limnology and Oceanography 60, 1076-1087 (2015).

72. Jackson, A. L., Inger, R., Parnell, A. C. \& Bearhop, S. Comparing isotopic niche widths among and within communities: SIBER - Stable Isotope Bayesian Ellipses in R. Journal of Animal Ecology 80, 595-602 (2011).

73. Layman, C. A., Arrington, D. A., Montaña, C. G. \& Post, D. M. Can stable isotope ratios provide for community-wide measures of trophic structure? Ecology 88, 42-48 (2007).

607 74. Wold, S., Sjöström, M. \& Eriksson, L. PLS-regression: a basic tool of chemometrics. 
609 75. Anderson, M., Gorley, R. N. \& Clarke, K. R. PERMANOVA + for PRIMER: Guide to $610 \quad$ Software and Statistical Methods. 1, 1:218 (2008).

611 76. Mullan, A. Influence of Southern Oscillation on New Zealand Weather. Proceedings of Western Pacific International Meeting and Workshop on TOGA-COARE (1996).

613 77. Francis, M. P., Hurst, R. J., McArdle, B. H., Bagley, N. W. \& Anderson, O. F. New 614 Zealand demersal fish assemblages. Environmental Biology of Fishes 65, 215-234 (2002).

615 78. Beentjes, M. P., Bull, B., Hurst, R. J. \& Bagley, N. W. Demersal fish assemblages along 616 the continental shelf and upper slope of the east coast of the South Island, New Zealand. New Zealand Journal of Marine and Freshwater Research 36, 197-223 (2002).

79. R Core Team. R: A language and environment for statistical computing. (2020).

80. SAS Institute. JMP. (2018).

620

81. Clarke, K. R. \& Gorley, R. N. PRIMER v6: User Manual/Tutorial. (PRIMER-E, 2006).

621

622

623

624

625

626 
631 O'Connell-Milne, Lucy Wing and Alex Connolly for providing some of the samples and data

632 used in this study and Tim Donlon for reviewing our work. We would also like to recognize the 633 contributions and support of our work from Mike Beentjes (NIWA), Kane Fleury (Otago

634 Museum), Carl Struthers, Clive Roberts and Andrew Stewart (Te Papa - National Museum of 635 New Zealand). Technical support was provided by Nicola McHugh, Robert van Hale, Russel 636 Frew, Dianne Clark, Doug Mackie, Linda Groenewegen, Reuben Pooley and from the Departments of Marine Science, Chemistry and Zoology at Otago University; Credit for fish pictures: Terry Wreford Hann. Funding: National Science Challenge: Sustainable Seas (4.1.1 Ecosystem Connectivity) grant to SW. LD was additionally supported by a University of Otago PhD scholarship; 


\section{Author contributions}

652 original draft; TI and JS: Conceptualization, resources, supervision; AS: Investigation, resources

653 and writing - review \& editing; SW: Conceptualization, funding acquisitions, resources,

654 supervision and writing - review \& editing. Competing interests: Authors declare no competing

655 interests; Data and materials availability: All data is available in the supplementary

656 spreadsheets "Durante_etal_data1.xlxs", "Durante_etal_data2.xlxs" and

657 “Durante_etal_data3.xlxs". Declaration: Collection and handling of animals were approved by

658 the University of Otago ethics committee under the protocol AUP-18-182 and were conducted in

659 accordance with relevant guidelines and regulations. Methods were reported in accordance with

660 ARRIVE guidelines.

661

662

663

664

665

666

667

668

669 
Fig. 1. Temporal trends of environmental data and fisheries activities. Temporal trend of the Marine Trophic Index for commercial fisheries in New Zealand waters ${ }^{21}$, Southern Oscillation Index (SOI), monthly temperature anomaly and its temporal trend (five year average low pass filter) ${ }^{22}$. SOI represents the fluctuation of atmospheric pressure in the edges of the tropical Pacific Ocean, where large negative and positive values indicate El Niño and La Niña events, respectively. Dashed line represents the linear regression of monthly temperature anomaly over the years. Straight black lines represent historical (prior 1996), and modern (after 2000) time periods analyzed in the present study. Fish samples were not available from the years between 1996 and 2000.

Fig. 2. Isotopic niche spaces. Average \pm standard error of the $\delta^{13} \mathrm{C}$ and $\delta^{15} \mathrm{~N}$ of fish species comprising different assemblages and sampled during historical (A, before 1996) and modern (B, after 2000) periods. Dashed ellipse represents the Standard Ellipse Area of all data points calculated through Bayesian inference, representing the total niche space of the community ${ }^{72}$.

686 Species are color coded by assemblages.

Fig. 3. Trophic structure anomaly through time. Average \pm standard error of the valuepredicted percentage phytoplankton supporting the food webs and the trophic level of fishes during the historical period (before 1996) in New Zealand. Predicted values were calculated from the species-specific relationship between each trophic parameter, latitude of sampling and specimens' total length for specimens collected after the year 2000 (modern specimens, table 
693 S5). Panels separate species with higher and lower trophic level, as well as relying on food webs 694 supported by more pelagic or coastal producers compared to modern predictions (i.e., historical 695 value minus modern predicted value). Symbols represent significant differences in value696 predicted percentage phytoplankton $(*)$ and trophic level $\left({ }^{\wedge}\right)$ between each period and modern 697 time period (table S3).

698

699

700

701

702

703

704

705

706

707

708

709

710 
712 Tables

713 Table 1. Sample sizes. Sample sizes for all species collected in different regions during

714 historical and modern time periods.

715

716

717

718

719

720

721

722

723

724

725

726

727

728 


\begin{tabular}{|c|c|c|c|c|}
\hline Species & Region & Historical & Modern & Total \\
\hline Blue cod & All & 12 & 58 & 70 \\
\hline \multirow[t]{3}{*}{ Parapercis colias } & Canterbury Bight & 6 & 30 & 36 \\
\hline & North of Banks Peninsula-Shallow & & 9 & 9 \\
\hline & Marlborough Sounds & 6 & 19 & 25 \\
\hline Elephant fish & All & 15 & 5 & 20 \\
\hline \multirow[t]{3}{*}{ Callorhinchus milii } & Canterbury Bight & 13 & 5 & 18 \\
\hline & North of Banks Peninsula-Shallow & 1 & & 1 \\
\hline & Marlborough Sounds & 1 & & 1 \\
\hline Gurnard & All & 20 & 25 & 45 \\
\hline \multirow[t]{3}{*}{ Chelidonichthys kити } & Canterbury Bight & 17 & 24 & 41 \\
\hline & North of Banks Peninsula-Shallow & 2 & & 2 \\
\hline & Marlborough Sounds & 1 & 1 & 2 \\
\hline Leatherjacket & All & 23 & 26 & 49 \\
\hline \multirow[t]{3}{*}{ Meuschenia scaber } & Canterbury Bight & 20 & 20 & 40 \\
\hline & North of Banks Peninsula-Shallow & 3 & & 3 \\
\hline & Marlborough Sounds & & 6 & 6 \\
\hline Barracouta & All & 8 & 15 & 23 \\
\hline \multirow[t]{3}{*}{ Thyrsites atun } & Canterbury Bight & 5 & 11 & 16 \\
\hline & North of Banks Peninsula-Shallow & 1 & & 1 \\
\hline & Marlborough Sounds & 2 & 4 & 6 \\
\hline Common warehou & All & 8 & 11 & 19 \\
\hline \multirow[t]{2}{*}{ Seriolella brama } & Canterbury Bight & 6 & 11 & 17 \\
\hline & Marlborough Sounds & 2 & & 2 \\
\hline Giant stargazer & All & 16 & 17 & 33 \\
\hline \multirow[t]{4}{*}{ Kathetostoma giganteum } & Canterbury Bight & 7 & 17 & 24 \\
\hline & North of Banks Peninsula-Deep & 2 & & 2 \\
\hline & North of Banks Peninsula-Shallow & 2 & & 2 \\
\hline & Marlborough Sounds & 5 & & 5 \\
\hline Red cod & All & 24 & 42 & 66 \\
\hline \multirow[t]{4}{*}{ Pseudophycis bachus } & Canterbury Bight & 7 & 19 & 26 \\
\hline & North of Banks Peninsula-Deep & 14 & 8 & 22 \\
\hline & North of Banks Peninsula-Shallow & 2 & 14 & 16 \\
\hline & Marlborough Sounds & 1 & 1 & 2 \\
\hline Spiny dogfish & All & 15 & 17 & 32 \\
\hline \multirow[t]{2}{*}{ Squalus acanthias } & Canterbury Bight & 12 & 17 & 29 \\
\hline & Marlborough Sounds & 3 & & 3 \\
\hline Tarakihi & All & 21 & 62 & 83 \\
\hline \multirow[t]{3}{*}{ Nemadactylus macropterus } & Canterbury Bight & 15 & 28 & 43 \\
\hline & North of Banks Peninsula-Shallow & 6 & 31 & 37 \\
\hline & Marlborough Sounds & & 3 & 3 \\
\hline Hapuka & All & 8 & 12 & 20 \\
\hline \multirow[t]{4}{*}{ Polyprion oxygeneious } & Canterbury Bight & 4 & 7 & 11 \\
\hline & North of Banks Peninsula-Deep & 1 & & 1 \\
\hline & North of Banks Peninsula-Shallow & 1 & & 1 \\
\hline & Marlborough Sounds & 2 & 5 & 7 \\
\hline Ling & All & 20 & 27 & 47 \\
\hline \multirow[t]{3}{*}{ Genypterus blacodes } & Canterbury Bight & 17 & 8 & 25 \\
\hline & North of Banks Peninsula-Deep & 1 & 11 & 12 \\
\hline & Marlborough Sounds & 2 & 8 & 10 \\
\hline Sea perch & All & 32 & 39 & 71 \\
\hline \multirow[t]{4}{*}{ Helicolenus percoides } & Canterbury Bight & 24 & 24 & 48 \\
\hline & North of Banks Peninsula-Deep & 1 & & 1 \\
\hline & North of Banks Peninsula-Shallow & 1 & 11 & 12 \\
\hline & Marlborough Sounds & 6 & 4 & 10 \\
\hline Hoki & All & 11 & 7 & 18 \\
\hline \multirow{2}{*}{ Macruronus novaezelandiae } & Canterbury Bight & 4 & & 4 \\
\hline & North of Banks Peninsula-Deep & 7 & 7 & 14 \\
\hline Lookdown dory & All & 18 & 12 & 30 \\
\hline Cyttus traversi & Canterbury Bight & 6 & & 6 \\
\hline & North of Banks Peninsula-Deep & 12 & 12 & 24 \\
\hline Orange roughy & All & 18 & 14 & 32 \\
\hline Hoplostethus atlanticus & Canterbury Bight & 6 & & 6 \\
\hline & North of Banks Peninsula-Deep & 12 & 14 & 26 \\
\hline Total & & 269 & 389 & 658 \\
\hline
\end{tabular}


731 Table 2. Temperature and environmental effects. Results of generalized linear models

732 (estimates \pm SE) describing the effects of abundance of pelagic prey (MUN), temperature (SST),

733 Southern Oscillation Index (SOI) and fisheries (MTI) on value - predicted percentage

734 phytoplankton supporting food webs and trophic level for the whole fish community.

735 Significance of species random effects are also presented in the form of $\mathrm{p}$ values. Value -

736 predicted represents the differences of historical trophic parameters to expected values

737 considering fish species, latitude, and total length (Fig. 3).

738

\begin{tabular}{lcccc} 
& $\begin{array}{c}\text { Percentage phytoplankton } \\
\text { Value - predicted }( \pm \mathrm{SE})\end{array}$ & $\mathrm{p}$ value & $\begin{array}{c}\text { Trophic level } \\
\text { Value - predicted }( \pm \mathrm{SE})\end{array}$ & $\mathrm{p}$ value \\
\hline All species & $\mathrm{n}=606$ & $\mathrm{n}=609$ & \\
Intercept & $-0.006 \pm 0.009$ & 0.562 & $-0.138 \pm 0.035$ & 0.0008 \\
MUN & $0.0002 \pm 0.0003$ & 0.517 & $-0.003 \pm 0.0008$ & $<0.0001$ \\
SST & $-0.004 \pm 0.012$ & 0.721 & $0.184 \pm 0.033$ & $<0.0001$ \\
SOI & $0.073 \pm 0.012$ & $<0.0001$ & $-0.164 \pm 0.032$ & $<0.0001$ \\
MTI & $0.057 \pm 0.044$ & 0.196 & $-0.711 \pm 0.116$ & $<0.0001$ \\
Random effect (Species) & 0.089 & & 0.019 & \\
\hline Adjusted R & 0.12 & & 0.24 \\
\hline
\end{tabular}




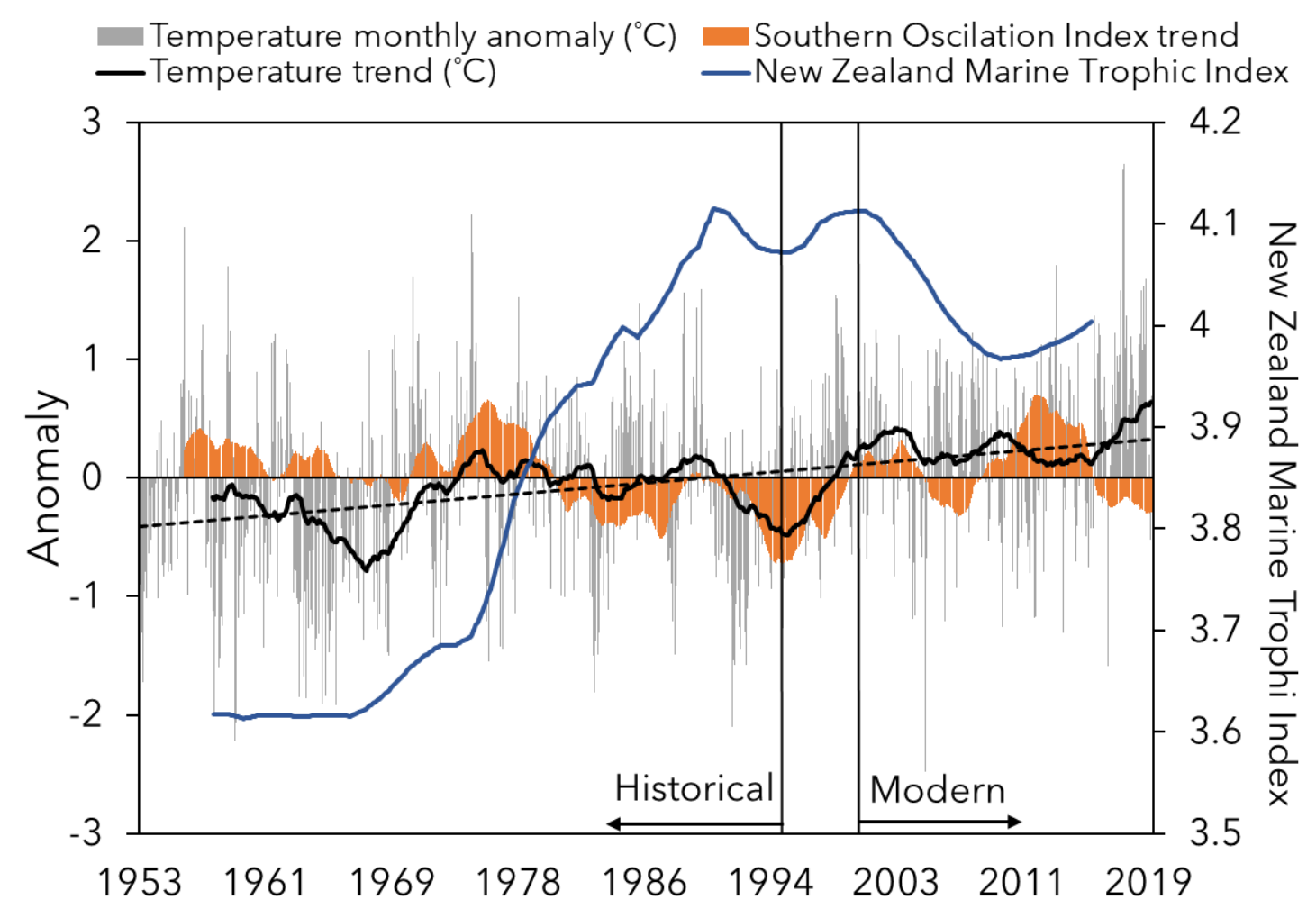

745 Fig. 1. Temporal trends of environmental data and fisheries activities. 


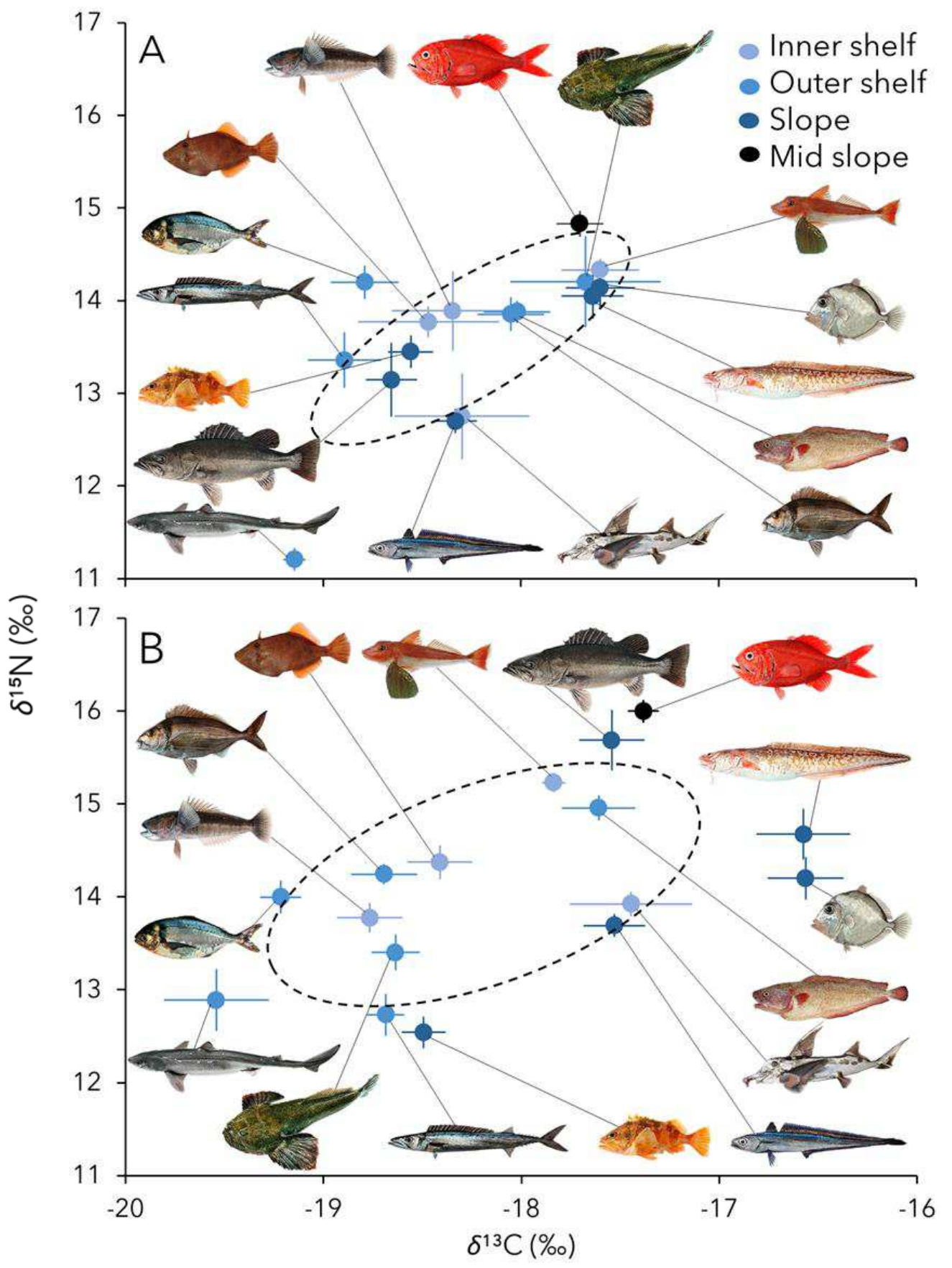

Fig. 2. Isotopic niche spaces. 


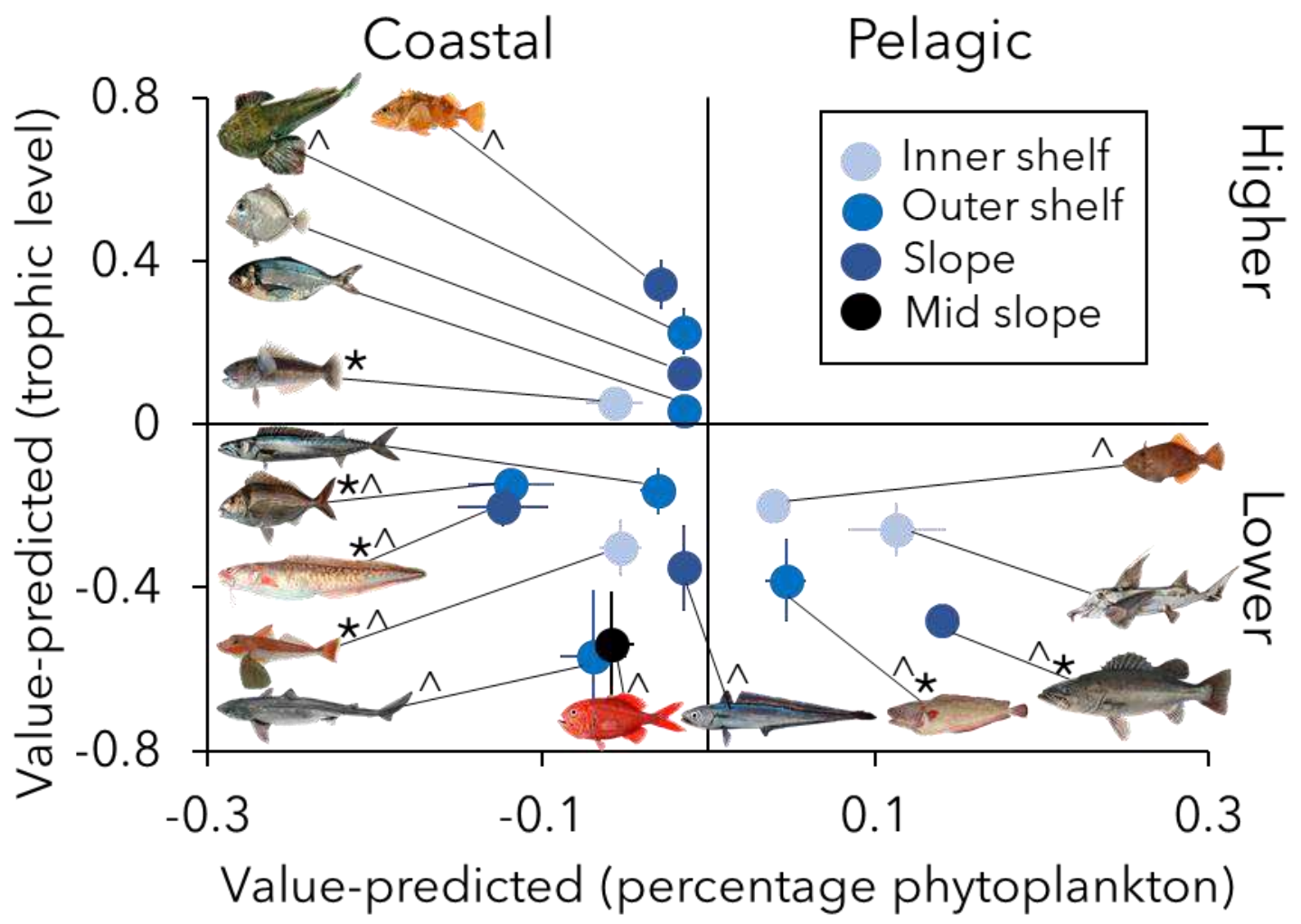

Fig. 3. Trophic structure anomaly through time. 


\section{Supplementary Files}

This is a list of supplementary files associated with this preprint. Click to download.

- DuranteetalSupMaterial240821.pdf 